\title{
METROPOLIS'TEN BIR HYDRIA
}

\section{BINNUR GÜRLER*}

1989 yılından beri Prof. Dr. Recep Meriç başkanlığında bilimsel kazıların sürdürüldüğü Metropolis antik kenti İzmir-Selçuk yolu üzerinde, İzmir iline bağlı Torbalı ilçesinin 5 km. kuzeybatısındaki Yeniköy ve Özbey köyleri arasında yer almaktadır. Strabon kitabı Geographika'da, Metropolis'in Smyrna-Ephesos yolu üzerinde, Ephesos'tan 120 stadion uzaklıkta olduğunu yazar' $^{1}$. Metropolis "Ana Tanrıça Kenti" anlamına gelmektedir. Meter Gallesia isimli ana tanrıçaya ait kült mağarası Uyuzdere'de Gallesion Dağının (Alaman Dağı) eteğindedir ${ }^{2}$.

Kent sikke lejantlarına göre Metropolis bir İon kentidir³. Metropolis'in ne zaman ve kimler tarafından kurulduğuna ilişkin yazılı belgelere henüz rastlanmamıs olmasına rağmen Seleukoslar zamanında birbirinden ayrı yerleşimlerin bir araya toplandığı bilinir. Metropolis'te de Seleukos krallığı zamanında Makedonyalı eski muhariplerle Arapkave ve Sinektepe höyük yerleşimlerinin katulımlarıyla geniş bir iskanın gerçekleşmiş olduğu düşünülmektedir ${ }^{4}$. Metropolis'te geniş bir iskanın gerçekleştiği Hellenistik dönem, Yunan kültürünün Yunanistan sınırları dışına çıkıp Akdeniz Bölgesi ve Ön Asya'da doğu kültürleriyle karışması ve kaynaşması sonucunda evrensel bir kültürün söz konusu olduğu dönemdir. Sanat ve bilimde uluslararası bir alış veriş, üretimde geniş ölçüde işbirliği vardır. Sanatç̧lar köklerinden koparak Hellenistik kültürün büyük merkezlerine katulırlar. Böylece ortamda yerel üretim tarzının sınırlarının kesin olarak saptanmasını engelleyen sürekli ve karşılıklı etkiler ortaya çıkar. Hellenistik kültür her şeyden önce bir şehir kültürüdür. Büyük kısmı kralların emriyle kurulmuş şehirlerde kaynaşan farklı topluluklar bütünü ve bunların iç içe geçmiş gelenek, hukuk ve sanat anlayışları bu kültürü oluşturur.

• Doç. Dr. Dokuz Eylūl Üniversitesi, Fen-Edebiyat Fakültesi, Arkeoloji Bölümü.

${ }^{1}$ Strabon, XIV, 632.

${ }^{2}$ R.Meriç, Metropolis in Ionien, Ergebnisse einer Survey-Unternehmung in den Jahren 1972-1975, Königstein/Ts. 1982 1982, Karte 1.

${ }^{3}$ Meriç 1982, 2 dipnot 8.

${ }^{4}$ Meriç 1982, 14. 
İnceleyeceğimiz beyaz zeminli (lagynos tarzı) hydria (Efes Müzesi Envanter No:9/25/91) Metropolis'te stoanın kuzey bölümünde sikkelerle tarihli tabakalardan oluşan bir dolguda ${ }^{5}$ ele geçen seramikler arasında yer almaktadır ${ }^{6}$. Bu dolgunun verdiği sonuçlar Hellenistik seramik genelinde kronoloji ile ilgili zorlukları Metropolis örnekleri için ortadan kaldırmaktadır. Burada beyaz zeminli seramikler için de önemli sonuçlar elde edilmiştir.

Dekorları açık renk zemin üzerine koyu renklerle yapılan seramikler vazo ressamlığının Hellenistik dönemdeki yeniliğidir. Bu tür dekorasyon Akdeniz'de yaygındır ${ }^{7}$. Süsleme fildişi astar üzerine dekoratif resim stilinde yapılır. Bu stilde süslenen başlıca form lagynos olduğu için süsleme "lagynos tarzı" olarak da adlandırılır. Karadeniz kıylarından Batu Anadolu kıylarına, Delos ve Kıbrıs'tan Mısır'a kadar geniş bir alanda bu tarz süslemeye sahip seramikler görülür ${ }^{8}$. Dekor için kullanılan renk turuncudan kahverengiye ve siyaha kadar değişir. Rengin koyuluğu firçaya alınan miktara ve darbenin kalinlığına bağlıdır ${ }^{9}$.

Beyaz zeminli seramiğin çıkıs yeri sorusu henüz cevaplanamamıştur. Stil ve teknik bir çok yerdeki geç klasik beyaz zeminli seramiklere bağlanır ${ }^{10}$. Seramik ihraç eden bir merkez olan Kırım'ın bu stilin çıkıs yeri olduğu düşünülmektedir ${ }^{11}$. Diğer bir görüş, kaynağın doğu Akdeniz bölgesi ve özellikle

${ }^{5}$ B.Gürler, Metropolis'in Hellenistik Dōnem Seramiği Ege Û̉niversitesi Sosyal Bilimler Enstitüsũ (yayımlanmamıs doktora tezi) İzmir 1994,Çizim 1-3.

${ }^{6}$ Gürler 1994, 3.

${ }^{7}$ G.Leroux, Lagynos, Paris 1913, 15-72; O. Vessberg, A. Westholm, The Hellenistic And Roman Periods In Cyprus, SCE Vol. IV, Part 3, Stockholm 1956, 40; F.O.Waage, Antioch on the Orontes IV, 1, Ceramics and Islamic Coins, Princeton N.J. 1948, 28; J.Schafer, Hellenistische Keramik aus Pergamon, PF 2, Berlin 1968,101; E.Boehringer, F.Krauss, Das Temenos für den Herrscherkult, AvP IX, Berlin-Leipzig 1937, 122-123; P.Hellström, Pottery of Classical and Later Date Terracotta Lamps and Glass, Labraunda Vol. II, Part 1, Lund 1965, 18; P.Bruneau, La vaisselle, L'ilot de la maison des Comediens, Delos XXVII, Paris 1970, 251; V.Mitsopoulos-Leon, Die Basilika am Staatsmarkt in Ephesos Kleinfunde, 1. Teil: Keramik hellenistischer und rỏmischer Zeit, FiE IX 2/2, Wien 1991, 75-76; J.W.Crowfoot, G.M.Crowfoot, K.M.Kenyon, The Objects From Samaria, Samaria-Sebaste: Reports Of The Work Of The Joint Expedition In 1931-1933 And Of The British Expedition In 1935, III, London 1957,176; F.F. Jones, The Hellenistic And Roman Periods, Excavations At Gözlü Kule, Tarsus Vol. I, Princeton 1950, 167;R.Tölle-Kastenbein, R.Felsch, U.Jantzen, Das Kastro Tigani, Die Bauten und Funde griechischer, römischer und byzantinischer Zeit, Samos Band XIV, Bonn 1974, 155.

${ }^{8}$ J.Boardman, "Greek Emporio: Excavations in Chios 1952-1955", BSA Supplementary Volume 62, Oxford 1967 174; Samaria III, 96.

${ }^{9} \mathrm{PF} 2,102$.

${ }^{10} \mathrm{PF} 2,101$; FiE IX 2/2, 75 .

${ }^{11} \mathrm{PF} 2,110$. 
buradaki thymiaterion formları üzerindeki süslemeler olduğu biçimindedir ${ }^{12}$. Bu tip süsleme M.Ö.2. yüzyılda yaygındır ${ }^{13}$.

Hydria süslemeli ya da düz üretilen bir formdur ${ }^{14}$. Metropolis hydriası geniş ağızh, yüksek boyunlu, çanak biçiminde gövdeli ve halka kaidelidir. Yüksekliği 18,8 cm., ağız çapı 14,5 cm. ve kaide çapı $8,2 \mathrm{~cm}$.dir. Dikey kulpunun üst kısmında elleri gövdesinin iki yanına birleşmiş, oturur biçimde bir figür, omuza birleştiği alt kısımda ise bir baş vardır. Kulplarında plastik figürler bulunan hydria örnekleri Yunanistan'da M.Ö. erken 6.yüzylldan itibaren yaygındır ${ }^{15}$. Bu stil doğu kökenlidir ${ }^{16}$. Hydrianın kulpundaki figürler koro plastik sanatıyla yakından ilişkilidir. Elleri vücudunun iki yanına bitişik, oturur ya da ayakta durur biçimde tasvir edilmiş giyimli kadın figürinlerine Pergamon'da sık rastlanır ${ }^{17}$. Hydrianın gövdeye doğru kıvrılan yatay kulpları Hadra'daki hydria örneklerinden bilinen bir özelliktir ${ }^{18}$. Miletos'da ele geçen minyatür hydria örneklerinin çoğunda bu tür yatay kulplar vardır ${ }^{19}$. Bu kulp formu M.Ö.3.yüzyıldaki Ptolemaios etkisiyle görülmektedir. M.Ö. 2.yüzyılda da devam eden bu özellik ya Anadolu üzerindeki Ptolemaios etkisi ya da bir Anadolu özelliği olarak açıklanmaktadır ${ }^{20}$.

Örneğimizde, mikalı hamur pembemsi bej renktedir. Mat görünümlü fildişi astarda bazı noktalarda sarı renk belirginleşmiştir. Astar sulandırılmış beyaz kille yapılır. Beyaz kil içerisinde bulunan çok az miktardaki demir fildişi tonunu verir ${ }^{21}$. Süslemelerde firçaya alınan malzeme miktarına ve dar-

${ }^{12}$ Boardman 1967, 175, Nr.891-899; Samaria III, 176, Abb.25; FiE IX 2/2, 75.

${ }^{13}$ Leroux 1913, 101; PF 2, 111;

O. Ziegenaus, G. De Luca, Das Asklepieion, AvP XI, 2, Berlin 1975, 206-208, Nr.101/2; Labraunda II, 1, 19; Samos XIV, 155; Delos XXVII, 251; FiE IX 2/2. Taf.89.

${ }^{14}$ E.Diehl, Die Hydria, Formgeschichte und Verwendung im Kult des Altertums, römischgermanisches Zentralmuseum zu Mainz, Mainz am Rhein 1964, 1 vd.; B.A.Sparkes, L.Talcott, The Athenian Agora XII, 1-2, Bmack and Plain Pottery of the $6^{\text {th }}, 5^{\text {th }}$ and $4^{\text {th }}$ centuries B.C., Princeton N.J. 1970, 53.

${ }^{15}$ D.M.Robinson, “New Greek Bronze Vases”, AJA 46, 1942, 187.

${ }^{16}$ Robinson 1942, 190.

${ }^{17}$ O.Zeigenaus, G. De Luca, Das Asklepieion,AvP XI, 1, Berlin 1968, Taf.41 no.135, 143; K.Nohlen, W.Radt, Kapikaya Bei Pergamon, AvP XII, Berlin 1978, Taf.27 no.31, 32. Bu figürinler Kybele kültünde yaygındır.

${ }^{18}$ A.Adriani, Annuarie du Musee Greco-Romain III(1940-1950), Alexandrie 1952, Fig.13, $15,16,20$,

${ }^{19}$ M.Pfrommer, "Zur Typologie der Miniaturhydrien vom Humeitepe" IstMitt 33, 1983, Abb.6:2, Abb.8, Abb.9:3-5.

${ }^{20}$ Pfrommer 1983, 83.

${ }^{21}$ PF 2, 102. 
benin kalınlığına bağlı olarak turuncudan kahverengiye ve siyaha kadar değişen tonların elde edilebilme imkanı dekorun resimsel karakterini artturır. Dekorasyonun bu stilinin paralelleri Attika'daki Batı Yamacı seramikleri üzerinde de izlenir ${ }^{22}$. Burada da resim elemanlan izlenimci bir etki verirler. Beyaz zeminli seramikler üzerindeki tasvirler Hellenistik dönem duvar resimleriyle ilişkilidir. Seramikler üzerindeki tasvirlerin benzerleri Delos'da Hellenistik dönem evlerindeki mozaiklerde ve duvar süslemelerinde görülür ${ }^{29}$. Her ikisinde de çizgiselden resimsele doğru bir değişim vardır.

Hydria üzerinde firça ile yapılmış süsleme boyun ve omuzda yoğunlaşır. Boyunda sarmaşık yaprakları, omuzda yatay kulplar hizasında firça vuruşlarıyla yapılmış süsler bulunur. Gövdenin alt kısmı ince ve kalın çizgilerle doldurulmuştur. Sarmaşık yaprakları ve firça darbeleri şeklindeki süslemelere Bat Yamacı seramiklerinde de sık rastlanır. Ephesos'daki bir lagynos omuz parçası üzerinde firça vuruşlarıyla yapılmış benzer süsleme görülür ${ }^{24}$.

Süslemede merkez ve taşra ayrımı izlenir. Batı Anadolu'da Menderes Bölgesi, Delos, İskenderiye, Kyrenaika ve Kırım'daki buluntular kalitelidir ${ }^{25}$. Kıbris ve Samos'da da bu tür seramikler ele geçmiştir ${ }^{26}$. Tarsus ve Antiokhei$a^{\prime}$ da ise çok az parça bulunmuştur ${ }^{27}$. Doğu Akdeniz'de en az iki ayrı üretim yerinden birinin yüksek kalitedeki çok çeşitli formlanyla Pergamon olduğu düşünülmektedir ${ }^{28}$. Üretimin Pergamon egemenliğindeki bir yerde yapılmış olması da mümkündür. Pergamon ithalleri çeşitli merkezlerde ele geçmiştir ${ }^{2}$.

Dekorasyonda genellikle natüralist motifler kullanılır: çelenkler, müzik aletleri, amphora, lagynos, kantharos gibi kaplar, yunus balıkları, sarmaşıklarla çevrili vazolar, sarmaşıklar, girlandlar ve kurdeleler. Bu dekorasyon öğeleri aynı zamanda değişen sosyal yapıyı ve bunun sanata yansımasını izlememizi sağlar. Erken dönemlerin artistik stilleri her zaman tek formda değildir.

\footnotetext{
${ }^{22}$ H.A.Thompson, "Two Centuries of Hellenistic Pottery", Hesperia 3, 1934,438-450.

${ }^{23}$ E.Pfuhl, Malerei und Zeichnung der Griechen I-II, Munich 1923, Taf.694 .

${ }^{24}$ FiE IX 2/2, Taf.89 E9.

${ }^{25}$ Boardman 1967, 891-899; Delos XXVII, 251 vd.

${ }^{26}$ SCE IV, 3, 40; Samos XIV, 155.

27 Tarsus I, Fig.132, 134; Antioch IV, 1, 28.

${ }^{28}$ A.Conze, Die Kleinfunde aus Pergamon, Berlin 1903, 17; PF 2, 101; A.Conze, Stadt und Landschaft, AvP I, 2, Berlin 1913, 277; E.Boehringer, F.Krauss, Das Temenos Für Den Herscherkult, AvP IX, Berlin-Leipzig 1937, 122.

${ }^{29}$ Samos XIV, 155; FiE IX 2/2, Taf.90 E12, E15.
} 
Üst sınıfin gösterişli sanat, alt sınıfin daha sade sanatu ile sık sık yan yana görülür. Hellenistik dönemde sosyal tabakadaki yapısal değişimle durum farklılaşır ${ }^{30}$. Sanata, özellikle seramik sanatuna yön veren en önemli değişiklik orta sınıfın meydana gelmesidir. Sanat eserleri için yeni ve önemli müşteriler olurlar. Onlar için görkemli ve gösterişli stiller alçak gönüllü bir ölçekle taklit edilir. Sanattaki klasik geleneğe yeni müşterilerin hoşlandiğı türler, natüralizm ve barok anlayış eklenir ${ }^{31}$. Hellenistik döneme kadar insan sanatun tek öznesidir. Şimdi ise çevresini oluşturan ve ona tercih edilen özneler tarafindan tahtından indirilir. Bu ticari bir dünyanın sonucudur ${ }^{32}$. Seramik dekorasyonunda insan figürünün çok az yer tutmasına karşılık bitkisel motifler, hayvanlar, çalgı aletleri sık kullanılır. Sarmaşıklar, çelenkler, kurdeleler, çalgı aletleri o dönem insanının içinde yaşadığı dünyanın önemli bir parçasıdır. Yazarların eserlerinde bu dünyanın tasviri vardır. Mestrius Plutarkhos'un "Marcus Antonius" adlı eserinde şu cümleler dikkati çeker: "Antonius, Ephesos'a girerken Bacchus rahibeleri gibi giyinmiş kadınlar, Satyr ve Pan kılığına bürünmüş adamlar ve delikanlılar ona öncülük ettiler ve bütün kent sarmaşıklarla, sarmaşık sarılmış değneklerle, harplarla, kavallarla ve flütlerle dolup taşıyordu" ${ }^{\text {"33 }}$.

Pergamon'da süslemenin kronolojik dizisi saptanmışur ${ }^{34}$. Burada dekorasyon stili çizgiselden resimsele doğru gelişir. Lagynos, kanne, tabak, destekli krater, thymiaterion ve pyxis formları bu tarzda süslenir. İzlenimci tasvirler çoğu kere natürmort hissini verir ${ }^{35}$.

M.Ö.2.yüzyılda yaygınlık kazanan beyaz zeminli seramiklere ait olan örnekler Pergamon'da en erken M.Ö.2.yüzyılın ilk yarısına ${ }^{36}$ tarihlenir. Pergamon'da Zeus Sunağı'nın altından beyaz zeminli seramiklere ait parça gelmemiştir. Asklepieion'dan gelen parçalar M.Ö.2.yüzyılın ilk yarısına aittir. Bu tür Pergamon'da M.Ö.2.yüzyıldan önce biliniyor değildir ${ }^{37}$. Ephesos'da

${ }^{30}$ B.Gürler, "Sanatun Sosyal Tarihinde Rasyonel Düşünce ve Illk Adım", Anadolu Sanat, Sayn 9, Mart 1999, 67-77.

${ }^{31}$ A.Hauser, The Social History of Art, Volume One, From Prehistoric Times To The Middle Ages, London 1977, 93.

${ }^{32}$ Hauser 1977, 95.

${ }^{33}$ Mestrius Plutarkhos, Marcus Antonius (Çev. Dr. Mehmet Özaktürk), Ankara 1992, 27.

${ }^{34}$ PF 2, 104.

${ }^{35}$ FiE IX 2/2, 76.

${ }^{36}$ PF 2, 112; AvP XI, 2, Taf.43 Nr.101/2, Nr.206-208.

${ }^{37}$ PF 2, 112; AvP XI, 2, Taf.43 Nr.101/2 (M.Ö.2.yüzyıl), Nr.206-208 (M.Ö.2.yüzyılın üçüncü çeyreğinden sonra). 
bu tarz süslemeye sahip kaplara ait parçalar M.Ö.200 civarındandır ${ }^{38}$. Diğer merkezlerde de M.Ö.2.yüzyılın başından önceye verilen örnek yoktur. Dik kulpu plastik süse sahip Metropolis hydriası beyaz zeminli seramik grubunun şimdiye dek saptanabilen en erken tarihli örneğidir. Bulunduğu tabaka M.Ö.3.yüzyllın ikinci çeyreğine, M.Ö.280-258'e ait, ön yüzlerinde defne çelengi içinde E ve $\Phi$ harfleri, arka yüzlerinde otlayan geyik yer alan iki Ephesos sikkesi ile tarihlenmiştir ${ }^{39}$. M.Ö.3.yüzyla ait bronz hydrialar arasında benzer formdaki plastik süslemeli örneklerini bulmamız da ${ }^{40}$ tarihini destekler. Bu form geç klasik dönemden beri devam etmektedir ${ }^{41}$ ve örneğimiz M.Ö.3.yüzylın ikinci çeyreğindeki uzantusıdır.

Priene'de bulunmuş olan bir hydriaya ait ağız, boyun ve kulp parçası eserimizin en yakın benzeridir ${ }^{42}$. Dudak profili aynıdır. Kulpu, kanatlarını dudağa doğru iki yana açmış bir Eros oluşturur. Priene örneğinde işçilik daha iyidir, detaylar daha ince ve titizdir. Metropolis'te stoanın kuzey bölümünde ele geçen hydria beyaz zeminli seramik grubunun şimdiye dek bilinen en erken örneğidir. Dolayısıyla benzeri olan Priene örneği de yakın bir tarihten olmalıdır. M.Ö.4.yüzyılın ikinci yarısına ait olan bronz hydria örneklerinde dikey kulpta plastik süsleme ve gövdeye doğru kıvrılan yatay kulplar görülür ${ }^{43}$. Eretria'da bulunmuş bir hydria form olarak eserimize benzer ${ }^{44}$. Örneğimiz de bu hydria gibi geç Klasik dönemden devam eden bir forma sahiptir.

${ }^{38} \mathrm{FiE}$ IX 2/2, 76, Taf.89-93.

${ }^{39}$ N. Breitenstein, W.Schwabacher, Sylloge Nummorum Graecorum. The Royal Collection of Coins and Medals, Danish National Museum, Copenhagen 1942, No.269; B.V.Head, A Catalogue of the Greek Coins of Ionia in the British Museum, London 1892, Ionia, PI.X-10.

${ }^{40}$ G.M.A.Richter, "A Fourth Century Bronze Hydria in New York", AJA 50, 3, 1946 , PI.XXVII, Fig.17.

${ }^{41}$ Richter 1946, PI.XXII, XXIV, XXVI-XXVIII.

42 Th.Wiegand, H.Schrader, Priene, Ergebnisse der Ausgrabungen und Untersuchungen 1895-1898, Berlin 1904, Abb.537 Nr.56.

${ }^{43}$ Richter 1946, PI.XXII, XXIV, XXVI, XXVII, XXVIII.

${ }^{44}$ Richter 1946, PI.XXVII , Fig.17. 
Binnur Gürler

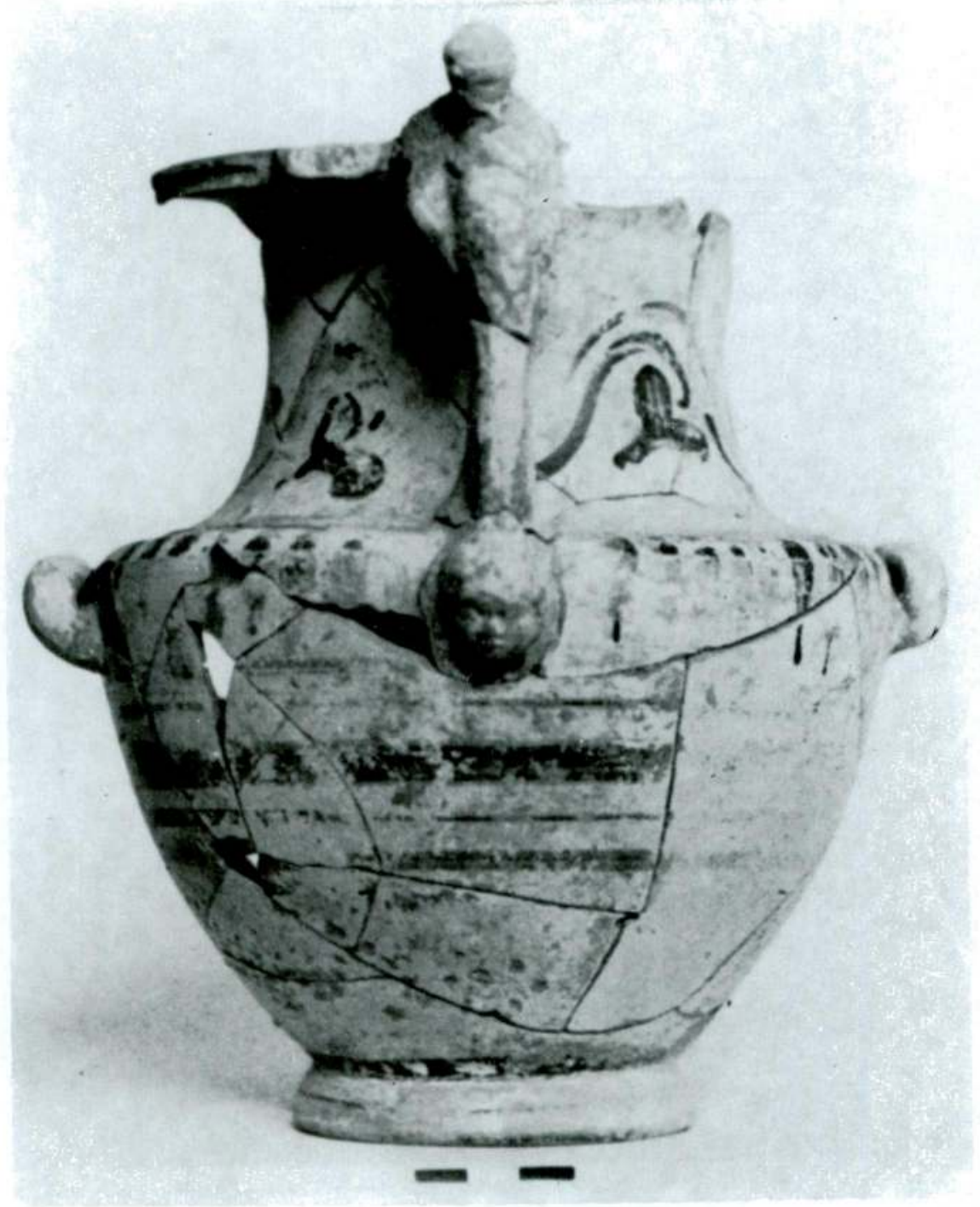

Res. 1 - Metropolis hydriası. 


\section{Binnur Gürler}

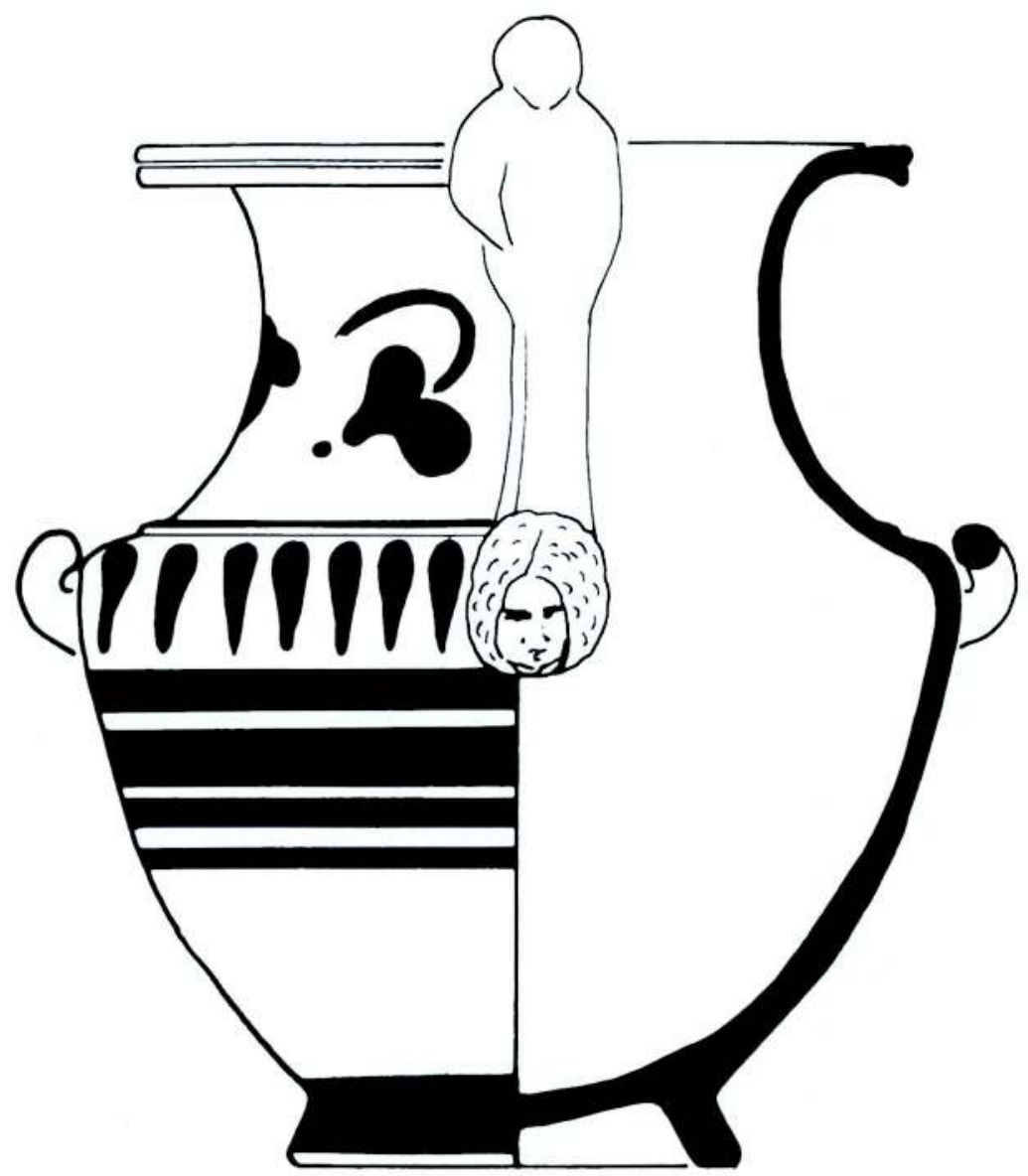

Res. 2 - Metropolis hydriası. Çizim. Ölçek: 1/1 